\title{
Narrativas monstruosas
}

\author{
Josalba Fabiana dos Santos I UFS/Paird
}

\begin{abstract}
Resumo: Em A menina morta, de Cornélio Penna, o monstruoso está inscrito no próprio ato de narrar. O romance (a narrativa maior) insere em seu interior uma série de pequenas narrativas que são feitas por escravas. Tanto o narrador principal quanto as narradoras revelam ocultando, contam sem contar, mostram escondendo. Cada história apresentada revela a monstruosidade do sistema patriarcal e escravocrata, mas isso nunca é feito de forma direta. Cabe ao leitor decifrar os enigmas para não ser enredado no labirinto sem fim que as narrativas propõem.

Palavras-chave: monstro, Cornélio Penna, A menina morta.
\end{abstract}

A menina morta (1954), de Cornélio Penna (1896-1958), é um romance que se desenvolve na segunda metade do século 19, numa fazenda produtora de café, situada às margens do rio Paraíba. A rica família que lá vive acabara de perder a filha mais nova. Essa menina deverá ser substituída pela irmã mais velha, Carlota, que estudava na Corte. No entanto, ao retornar à propriedade,

1. Este artigo faz parte do projeto de pesquisa "O monstro e a nação: a obra de Cornélio Penna como reflexo da violência”, que é financiado pelo Programa de Auxílio à Integração de Docentes e Técnicos Administrativos Recém-Doutores às Atividades de Pesquisa (Paird), da Universidade Federal de Sergipe. 
não encontra a mãe, Dona Mariana, que deixara de lá residir. Pouco antes, seu pai, o Comendador, quase levara um tiro de um dos escravos, Florêncio. Carlota se depara com uma família em luto e desestruturada; sua função é amenizar as dores e para isso ela deverá se casar com João Batista, filho de uma parenta do Comendador e de um ministro do Império, o Conde do Meal. Poderia ser uma narrativa qualquer em que uma jovem se sacrifica num casamento destituído de amor. No entanto, o matrimônio não se realiza. E se projeta para o leitor uma infinidade de perguntas destituídas de respostas. Em que circunstâncias a menina morreu? Qual era o seu nome? Por que o Comendador tem pressa de que ela seja esquecida? Por que Dona Mariana deixa o Grotão? Por que o escravo tenta matar o Comendador?

Este trabalho não pretende sanar essas dúvidas. A intenção é discutir a função da omissão e do silêncio em A menina morta. O narrador conta uma história eliminando muitas informações, desorientando o leitor. Agrava a situação o fato de que há pequenas narrativas paralelas à maior, produzidas pelas escravas e que contribuem ainda mais para a desorientação. É o "Decifra-me ou te devoro" edipiano que retorna. A narrativa se coloca de maneira monstruosa, pois na medida em que se desenvolve destrói parte daquilo mesmo que produz, como Crono devorando os próprios filhos. E a comparação com Crono não é de forma alguma gratuita, pois é conhecida a associação semântica desse deus com o tempo (cronos). ${ }^{2}$ No pensamento de Paul Ricour, desenvolvido ao longo de Tempo e narrativa, ${ }^{3}$ pode-se observar a indissociabilidade entre essas categorias: toda história se constrói no tempo, não há como contar algo destituído de tempo. Na verdade, o próprio tempo se constrói através da história - ficcional ou não. No entanto, na medida em que a narrativa se escoa como um fluxo, ela invariavelmente aponta para o seu fim, para o seu próprio término. A narrativa toda se devora. Tal devoramento é suscitado inclusive pelos enigmas que vão sendo fartamente distribuídos ao longo do romance. Ou seja, aquilo que é narrado já chega ao leitor meio desintegrado, como que faltando pedaços.

Se um segredo é conhecido, não existe e, se não é conhecido, não é segredo. O segredo é a fronteira entre o saber e o não saber ou, como prefere Josefina Ludmer: "A fronteira é o lugar do segredo e do "mais além."”" Ele é o claro-

2. BRANDÃO. Mitologia grega, p. 198, v. 1.

3. RICCEUR. Tempo e narrativa, v. 1, v. 2, v. 3.

4. LUDMER. O corpo do delito: um manual, p. 131. 
escuro da narrativa: quase se pode vê-lo, mas não se o vê. O segredo só existe porque se imagina, projeta-se e se inventa um contorno para ele. Está posicionado entre o que se diz e o que não se diz, entre o que se deseja saber e o que não se queria conhecido jamais. A narrativa corneliana está cheia de cofres dos quais nunca se obtém o segredo - nem o de abertura nem o de conteúdo. Fronteira (1935), o primeiro romance do autor, por exemplo, é um diário, o gênero por excelência da simulação do segredo. O diário, em geral, pertence ao âmbito do restrito. Aquilo que se escreve corresponde àquilo que não se deseja sabido. Se se quisesse revelar seu conteúdo, bastaria dizê-lo a alguém. Em contrapartida, se realmente não houvesse interesse em revelar segredos, estes nem sequer seriam escritos. Daí o caráter simulador do diário: aparece como objeto íntimo, mas está sempre aberto à possibilidade de uma revelação pública. Aquele que escreve não tem domínio total sobre o destino de suas palavras.

O mistério e o segredo são armas - de defesa e de ataque. Conhecer o que não se deve conhecer pode ser um trunfo ou um perigo. Pode-se inventar um segredo ou um mistério para se controlar alguém. As mucamas do Grotão tecem narrativas para dominar os moradores - um domínio aparentemente irrelevante se comparado ao dos brancos sobre elas, mas um domínio. Para Foucault, não se deve tomar o poder como um fenômeno exercido por um indivíduo sobre outros ou de um grupo sobre outros grupos. Ele afirma:

O poder deve ser analisado como algo que circula, ou melhor, como algo que só funciona em cadeia. Nunca está localizado aqui ou ali, nunca está nas mãos de alguns, nunca é apropriado como uma riqueza ou um bem. O poder funciona e se exerce em rede. Nas suas malhas os indivíduos não só circulam mas estão sempre em posição de exercer este poder e de sofrer sua ação; nunca são o alvo inerte ou consentido do poder, são sempre centros de transmissão.'

Narrando algumas histórias e omitindo outras, as escravas negociam e negaceiam as fronteiras que as distanciam e aproximam dos senhores. O mistério se constrói no tempo: no decorrer das narrativas que são contadas e na distância que as separa dos ouvintes. Afastadas cronologicamente daquilo que é narrado, as personagens só podem confiar nas narradoras, pois não têm nem tiveram acesso direto ao passado. Mas o mistério também se constitui no espaço: no vazio e na

5. FOUCAULT. Soberania e disciplina, p. 183. 
penumbra de cada sala e de cada corredor. É na intersecção entre o tempo e o espaço que o mistério se produz: nas fissuras de ambos, sempre cabe um monstro.

Fatores tais como o isolamento da casa-grande, ruídos inexplicáveis, atmosfera noturna, possibilidade constante de uma revolta dos escravos e o medo infligido pelo Comendador contribuem para o estado de horror no qual todos vivem. Também o fato de a casa lembrar um labirinto exacerba os enigmas. Desorientado, o administrador da fazenda é obrigado a se valer da ajuda de uma escrava:

O senhor Justino, diante da porta do quarto de vestir dos senhores, parou, e despediu com aspereza a pretinha que tomara como guia, pois perdera-se na confusão de entradas de salas e corredores daquela casa que lhe parecera sempre um palácio encantado e proibido. ${ }^{6}$

A comparação hiperboliza o mistério que constitui a casa. Um lugar misterioso abre fissuras para a criação de monstros. A casa-grande não é acolhedora como um lar. É um labirinto e como tal causa insegurança: aquele que entra está perdido e terá problemas para encontrar a saída - se a encontrar. Na mitologia clássica grega, o labirinto é a morada do monstro. Segundo Paul Diel, ${ }^{7}$ o Minotauro, que habitava um labirinto subterrâneo, representava a dominação perversa exercida por Minos, o rei de Creta, sobre os seus súditos. Filho de sua esposa e de Posídon, a monstruosa criatura precisa ser escondida porque é motivo de vergonha. No entanto, também necessita de alimento para continuar vivendo. A dominação perversa é facilmente identificada em A menina morta na figura do Comendador. É ele quem subjuga os escravos do Grotão.

A monstruosidade que a casa encerra se reproduz na narrativa, no que é dito e no que não o é. O silêncio e a linguagem podem ser ao mesmo tempo formas de domínio e de transgressão. Não se deve lê-los de maneira redutora: um como resignação e o outro como violação às regras impostas pelo sistema patriarcal-escravocrata. Silêncio e linguagem são intercambiáveis e servem tanto para exercer poder quanto para sofrer a sua violência, dependendo da circunstância e do sentido que retêm. O Comendador, símbolo do poder, pouco fala e, quando anuncia que tem algo a dizer a Carlota, termina por não dizer nada:

6. PENNA. A menina morta, p. 37.

7. Citado por BRANDÃO. Mitologia grega, , v. 3, p. 160-161. 
O pai não a olhava, e tinha estampada no rosto a perplexidade mais completa. Parecia procurar encontrar o caminho, palavras libertadoras que esclarecessem a ele próprio, na missão a si mesmo dada em fazer a filha aceitar a situação, o modo de viver encontrado; ou antes, que viesse dar forma à desordem, dar realidade à mentira reinante em sua casa, sustida apenas pelo hábito de respeito. ${ }^{8}$

Observa-se nessa passagem que a arquitetura labiríntica da casa-grande é transferida para a linguagem: o Comendador tenta encontrar o caminho, as palavras certas para falar com sua filha, mas não as acha. Dona Mariana, principal opositora do patriarca, igualmente pouco diz. Normalmente o leitor nem sequer tem acesso ao pensamento dessas duas personagens. Ao mesmo tempo que se tem o Senhor impondo suas regras mais pelo olhar do que pela palavra, tem-se sua esposa resistindo emudecida. Pode parecer uma atitude passiva, no entanto controlar a linguagem é bem mais fácil do que controlar o silêncio. ${ }^{9}$ A silenciosa resistência da Senhora impossibilita qualquer represália: não há nada para dizer a quem nada diz. Dona Mariana compreende perfeitamente a "força corrosiva do silêncio". 10

Costuma-se associar silêncio com morte e linguagem com vida. Todavia, a morte em Cornélio Penna pode ser infinitamente adiada pela memória. Se é a memória que adia a morte, é a narrativa (linguagem) que perpetua a vida. Dessa forma, o intercâmbio entre silêncio e linguagem fica evidente. Um não exclui o outro nem é mero complemento. A linguagem seria apenas barulho sem sentido e sem fim se não existisse o silêncio. O silêncio está no desvão de cada palavra. É esquecimento, mas também é memória porque, na condição de lacuna, abre-se para a possibilidade de ser lembrado. Como pergunta Walter Benjamin: "Não existem, nas vozes que escutamos, ecos de vozes que emudeceram?" ${ }^{11}$ Entre o que se narra e o que deliberadamente é omitido despontam fugazes respostas para as quais o leitor deve estar atento. "A verdadeira imagem do passado perpassa, veloz. O passado só se deixa fixar, como imagem que relampeja irreversivelmente, no momento em que é reconhecido." ${ }^{12}$ As inúmeras lacunas presentes no texto remetem ao

8. PENNA. A menina morta, p. 250.

9. ORLANDI. As formas do silêncio: no movimento dos sentidos, p. 38.

10. ORLANDI. As formas do silêncio: no movimento dos sentidos, p. 13.

11. BENJAMIN. Sobre o conceito da história, p. 223.

12. BENJAMIN. Sobre o conceito da história, p. 224. 
nome da fazenda: Grotão. A grota é a fissura (silêncio) aberta na terra pelas enxurradas (linguagem). Visto que a propriedade decai, a grota pode ser lida como ruína: esse é um dos sentidos do silêncio, o da sua força corrosiva.

As omissões, os silêncios da narrativa podem ser lidos. A redução da menina morta a um epíteto tem significado. Dar-lhe um nome é colocá-la na condição de viva, uma condição da qual ela só desfruta na memória dos moradores da fazenda. Quando o Comendador manda retirar seu retrato da parede, abre-se novo silêncio em torno dela. Há um lugar deixado vazio que deverá ser preenchido por Carlota. A ausência da menina, somada à interdição dos rituais de morte e à retirada do seu retrato, confunde silêncio e silenciamento. De certa maneira, o silêncio emana do silenciamento imposto pelo Senhor. A criança resiste a cada ato deliberado de eliminá-la - não falando, pois não pode mesmo falar - silenciosamente, pela sua falta. Viva, ela dissimulava os conflitos no Grotão; morta, ela exacerba a falta, aquilo que não há. O fim da sua existência evidencia o ódio e, por extensão, a ausência de amor.

O silêncio pode ser resistência quando quem silencia se recusa a se integrar a um sistema ou compactuar com ele. Os excluídos - negros, mulatos, mulheres, crianças, pobres, agregados, loucos - podem se calar como forma de oposição. Sendo assim, o silêncio não é mera falta; ele é atitude, tem sentido, significa. ${ }^{13}$ As vozes dos negros foram marcadas pelo silêncio e pela morte, ficaram quietas na fissura da história. Mas dessa lacuna, atesta Benjamin (1993), também é feita a história. O silêncio produz literatura em Cornélio Penna, afirma Wander Melo Miranda, ${ }^{14}$ pois até "palavras são cheias, ou melhor, são carregadas de silêncio". ${ }^{15}$ A violência está inscrita no silêncio da narrativa para vez ou outra ser respondida com lamentos, gemidos e gritos proferidos pelas escravas no momento em que são açoitadas:

As portas já haviam sido fechadas e dentro em pouco gritos selvagens, ulos e súplicas gaguejadas, vieram lá de dentro mas perderam-se no terreiro imenso, e eram logo abafadas por ameaças ditas em tom surdo para que os ecos não chegassem até a residência, aquela hora ainda envolta em sombras e serenidade... mas, se chegassem até lá, poderiam ouvir que soluçavam: - Sinhazinha! Sinhazinha! ${ }^{16}$

13. ORLANDI. As formas do silêncio: no movimento dos sentidos, p. 33.

14. MIRANDA. Posfácio, p. 473.

15. ORLANDI. As formas do silêncio: no movimento dos sentidos, p. 69.

16. PENNA. A menina morta, p. 74. 
Parece surpreendente que as cativas dirijam sua súplica à menina, à sinhazinha, que na condição de morta nada podia fazer. Há um descompasso temporal: como a criança intercedia a favor dos escravos quando viva, acredita-se que ela continuaria a defendê-los mesmo depois de morta. Todavia, a repetição do vocativo pode não ser uma súplica, mas uma queixa, visto que os castigos ocorriam mesmo quando ela ainda vivia. Só muito depois desse episódio, as súplicas ou queixas conseguem atravessar as grossas paredes da casa-grande. Carlota, a substituta da irmã, "descobre" a sala dos castigos. Os escravos eram martirizados todos os dias no Grotão. O narrador não o diz, mas é justamente porque não o diz que se torna claro ser essa a regra. O silêncio que emoldura a visão que Carlota tem dos suplícios faz da cena um grito.

Além de o silêncio significar por si só, também é fundador, pois produz linguagem, ${ }^{17}$ que, no caso, instaura uma nova forma de ver e de dizer. Como o Comendador e Dona Mariana pouco falam, abrem brechas para outros falarem deles e por eles. É assim que Dona Virgínia, que ocupa o principal lugar entre os parentes agregados, sente-se à vontade para fazer toda sorte de intrigas em torno do nome da Senhora e de sua família:

O Comendador autorizava com o seu silêncio que se ferisse até o sangue aqueles senhores desvairados pelo excessivo poder muitas vezes reunido em suas mãos, cuja memória se desrespeitava friamente, e as precauções e reticências ironicamente tomadas faziam ainda mais insultantes as alusões. Ela [Celestina] era a única, além da Senhora, a ser visada, mas agora viria Carlota, em cujas veias corria a mesma herança, e tinha o nome assim maculado (...).

É interessante para o Comendador que o fluxo de maledicência dirigido à esposa não cesse. Ele não se importa nem mesmo com a possibilidade de seus filhos e filhas serem atingidos. Cala-se para que as palavras maldosas continuem a macular a família de Dona Mariana e em especial a ela própria. Celestina igualmente não se manifesta, mas o seu silêncio advém da sua condição dentro da hierarquia do Grotão: prima afastada da Senhora, era órfã e pobre. Também é com silêncio que o Comendador responde a comentários maldosos feitos por

17. ORLANDI. As formas do silêncio: no movimento dos sentidos, p. 23. 18. PENNA. A menina morta, p. 178. 
Dona Virgínia sobre as vantagens da fazenda do seu irmão, o Visconde. Naturalmente são duas situações bastante distintas, portanto o silêncio tem um caráter diferenciado em cada uma delas. No caso dos irmãos, como há ódio e inveja entre eles, o silêncio obriga que a prima se cale, dessa vez interrompendo o fluxo de intrigas:

- Primo Comendador, como são os dunquerques de marqueterie que apareceram à venda agora na Corte?

O Senhor abaixou os olhos depressa para o prato colocado diante dele, ainda bem quente, pois fora passado em água fervendo para conservar o calor, e nada respondeu. Parecia não ter querido ver o brilho de pequeno triunfo que fazia reluzir as pupilas de sua parenta, nem o riso preso nos cantos de seus lábios. Dir-se-ia que se envergonhava da pequena traição de que estava sendo vítima, sentia a ingratidão que ela representava e não queria torná-la mais viva, lendo-a naquele rosto visto tantas vezes banhado de lágrimas irreprimíveis.

Apesar de prima e aliada, Dona Virgínia não se furta de distribuir comentários maldosos nem mesmo ao seu protetor, o Comendador. No fundo ela se reconhece como mero instrumento nas mãos do poderoso parente. Como sabe que o Visconde - e o próprio título indica isso - está socialmente mais bem posto do que o irmão, ela se aproveita da situação para humilhá-lo. Referindo-se aos dunquerques de marqueterie, objetos possuídos pelo Visconde, ela expõe sua riqueza e seu luxo. Dona Virgínia joga com a sua posição privilegiada dentro da casa, ora criticando a família de Dona Mariana para agradar ao primo, ora espezinhando a ele próprio para se sentir mais forte - ou menos frágil.

Mas há outras resistências significativas em torno da casa-grande. Sons de tambores de um quilombo distante, ouvidos no Grotão, somente são audíveis por causa do silêncio proporcionado pela noite. O que comunicam repercute como provocação àqueles habitantes contaminados pelo medo de uma revolta. Em contrapartida, o silêncio dos escravos da fazenda - contraposto ao ruído dos negros ocultos na mata - está longe de significar contenção. Eles também se valerão da linguagem para demonstrar insatisfação, mas, como ela é controlada com cuidado, torna-se necessário fazer as lacunas significarem.

19. PENNA. A menina morta, p. 85. 
Inicialmente são escravos fugidos, não necessariamente do Grotão, que amedrontam os brancos. ${ }^{20}$ Mas após a viagem do Senhor para a Corte os problemas aumentam, pois é de uma possível revolta na fazenda que se fala.

De quando em quando chegavam até ela [Carlota] em ondas os sons quebrados de gargalhadas, mas tinha ouvido as ordens deixadas por seu pai antes de partir e sabia terem sido as armas embaladas distribuídas aos feitores e aos guardas, com a recomendação de atirar ao primeiro sinal de revolta. Assim estava informada de que toda aquela paz, na aparência nascida da ordem e da abundância, todo aquele burburinho fecundo de trabalho, guardavam no fundo a angústia do mal, da incompreensão dos homens, a ameaça sempre presente de sangue derramado.

Associando a possibilidade de uma revolta ao mal e ao sangue, Carlota, ainda dividida entre escolher o lado do pai ou o da mãe, não compreende a dimensão da exploração à qual os cativos - e os forros inclusive - são expostos. A senzala é um perigo iminente, "pronta para o salto de onça". D. Virgínia vendo a casa sem administração, um "hotel sem gerência" nas suas palavras, passa a considerá-la vulnerável a ataques dos escravos, ataques que na sua própria fazenda, a Goiabeiras, ela soubera controlar, ${ }^{24}$ o que não lhe evitou a ruína mesmo assim. Ironicamente, a ruína dos brancos é prejudicial aos escravos, que a rigor só trocariam de donos. A maior de todas as ironias, no entanto, é que alforriados não podem mais ser vendidos e são lançados à própria sorte. Talvez por isso Carlota perceba emanações ameaçadoras advindas da senzala após ter libertado todos os escravos do Grotão:

Ela parou nos degraus de pedra e estendeu os braços em gesto de defesa, pois tinha a obscura impressão de que perigos mortais a espreitavam escondidos naqueles ângulos negros das paredes ou ocultos pelas janelas e portas hostilmente fechadas das senzalas em sinal de morte e de abandono. ${ }^{25}$

20. PENNA. A menina morta, p. 283.

21. PENNA. A menina morta, p. 312.

22. PENNA. A menina morta, p. 313.

23. PENNA. A menina morta, p. 355.

24. PENNA. A menina morta, p. 424.

25. PENNA. A menina morta, p. 461. 
Mas essa Carlota é muito diferente da jovem frágil que chegara ao Grotão, pois seu domínio esvaziou as senzalas, que não são mais ameaçadoras de fato, e no mesmo instante sua visão se altera:

Como um escudo que deslizasse diante dela, mantido e levado por sua vontade renovada, sentiu que caminhava à sua frente outra Carlota, mais pura e de linhas mais retas e simples, capaz de viver "apenas". Com o medo inexplicável que prendera seus movimentos, que limitara e constrangera a vitalidade de seu corpo todo aquele tempo, agora se dissipavam diante da outra os sinais humanos de poder e de dominação, cuja força a tinham mantido prisioneira. ${ }^{26}$

O caráter destrutivo de Carlota é facilmente relacionado à potência que todo o monstro encerra, ou seja, não há monstruosidade sem morte, mutilação ou algum tipo de destruição. ${ }^{27}$ Monstro é uma metáfora reservada para determinadas personagens em A menina morta, e o mais interessante é que quase todas são mulheres - Dona Mariana, a menina e Carlota - ou escravos - especialmente escravas. Das cativas se diz que em conjunto são como um "dragão fabuloso, cheio de escamas e de protuberâncias, todo de cinza e preto, parecendo não tocar no solo da estrada com seus pés múltiplos e quase invisíveis," ${ }^{28}$ quando se encaminham a Porto Novo, a vila próxima, para prestarem suas últimas homenagens à sinhazinha morta. Dragão remete a força e o fogo que emana é destruidor, como cabe a um monstro. Trata-se de um ser fabuloso, portanto sem correspondente na realidade, daí as escravas se enfraquecerem assim que são alcançadas na mata pelos feitores. Mas esse momento de fragilidade não pode ser confundido de maneira alguma com ausência de poder, visto que dispõem de outros recursos para aterrorizar.

A função de um narrador é contar uma história, conduzir seu ouvinte ou leitor do início ao fim. O narrador é um guia que levará aquele que o ouve ou lê por caminhos desconhecidos. A literatura é uma espécie de jogo e o texto propõe as regras de como ele deve ser jogado. As narradoras negras em Cornélio Penna mais desorientam do que orientam os "jogadores". Diante de suas histórias, restam ouvintes atônitos e perplexos. Celestina, a prima pobre, segundo Luiz

26. PENNA. A menina morta, p. 461.

27. CARROLL. A filosofia do horror ou paradoxos do coração, p. 64 .

28. PENNA. A menina morta, p. 72. 
Costa Lima, ${ }^{29}$ é "cativada" por Dadade, uma antiga escrava que agora se encontra paralítica. A expressão é muito feliz porque inverte o estado de ambas. Dadade passa de escrava a livre, pois é ela quem "dá as cartas". Enquanto Celestina passa de livre a escrava, assumindo a identidade de Sinhá Clara, antiga senhora do Grotão, ao seguir as regras do jogo que lhe é proposto. Dadade "faz de conta" que confunde Celestina com Sinhá Clara. Sabe-se que a prima pobre pouco significa na hierarquia da família, mas isso não é importante. Fundamental é que na relação com Dadade ela pense estar trapaceando a negra velha, quando é esta quem a trapaceia. Até que Celestina cai doente e pede a Carlota que a substitua: entretanto, a prima rica interrompe o equívoco, pois não fica confortável com a situação.

Ao dar ouvidos às histórias da escrava, ao contrário de Carlota, Celestina passa a ser dominada, desempenha o papel que aquela lhe atribui. Esse pequeno engano é o reflexo de outros, pois em vários momentos da narrativa as personagens se sentem "em cena". Carlota não aceita a constante representação a que todos se sujeitam no Grotão. Interromper a farsa com Dadade é uma metáfora da interrupção maior: não casar com João Batista, o noivo escolhido pelo Comendador, é destruir o jogo proposto/imposto pela família. Todavia, ao se esquecer de alforriar Dadade ao final do romance, revela a inutilidade do seu ato. Dadade não precisava da liberdade concedida pelos brancos. Ao se tornar a narradora, inverte seu estado: liberta-se. Afinal, velha, inválida e retida num catre, qual opção no mundo real a deixaria mais longe do cativeiro do que a ficção?

Criando narrativas assustadoras, as escravas cativam seus ouvintes, formam e deformam a história da família Albernaz. A transformação e a deformação são características do monstruoso. ${ }^{30}$ Perturbada a ordem natural, surge o horror. ${ }^{31}$ As narradoras mostram aos habitantes do Grotão a sua própria face, que eles forcejam por não reconhecer: olham-se no espelho daquilo que ouvem e não se veem. Não veem a violência que praticam ou da qual são cúmplices, por isso não compreendem o que ouvem.

Dadade conta a Celestina a história da mucama que não tinha rosto e que teria servido numa única noite a uma ancestral do Senhor. Agastada com o serviço das mucamas de sempre, essa antiga senhora as dispensa e tem o quarto invadido por uma que nunca vira e que a prepara para o sono como nenhuma

29. LIMA. A perversão do trapezista: o romance em Cornélio Penna, p. 153.

30. NAZARIO. Da natureza dos monstros, p. 45.

31. CARROLL. A filosofia do borror ou paradoxos do coração, p. 31. 
outra o fizera até então. Enigmática, a nova mucama fala numa linguagem incompreensível, indecifrável. Curiosa, a antiga senhora tenta descobrir a identidade da escrava, mas quando força uma situação que a iluminaria repentinamente, descobre-a sem rosto. ${ }^{32}$ A desconhecida mucama é um monstro, pois aterroriza a antiga senhora, além de destruir a lógica segundo a qual os escravos temeriam os brancos e assim se resignariam a sua condição. Essa escrava sem rosto simboliza a falta de identidade ou individualidade dos negros segundo a ótica escravocrata. Afinal, a fazendeira não vê o rosto e tampouco compreende a linguagem usada pela negra. Assustadora, essa pequena narrativa embutida na narrativa maior remete Celestina a outras que revelavam a "crueldade dos antigos senhores". 33 As negras e mulatas narradoras, como o narrador principal, contam histórias que fazem a eles e ao leitor "perder-se no labirinto de suas narrativas, cheias de lacunas e sobrecarregadas de detalhes e de digressões inúteis" ${ }^{34}$ - parecendo inúteis, mas não o sendo necessariamente. Assim, labirínticas, essas histórias não apenas simulam o romance em questão, mas igualmente simulam a arquitetura da casa-grande, com muitos corredores e quartos que faziam os mais desavisados se perderem.

É a mesma Dadade, da qual diziam ser feiticeira de "pretendido poder maléfico," ${ }^{35}$ quem menciona a presença indesejável de um bode preto no quadrado, ${ }^{36}$ espaço fronteiriço que separa e aproxima forçosamente os escravos dos senhores. O bode preto parece ser uma invenção da velha mucama, mas de repente é visto por Carlota justamente após visitar sua futura sogra, a Condessa, na fazenda denominada ironicamente pelo autor como Paraíso. Além de ver o bode preto, símbolo do Mal reinante nas duas propriedades, Carlota também toma consciência pela primeira vez dos castigos infligidos aos negros: enfim, ela vê o Mal que a rodeia em toda a sua dimensão. Ele está inserido inclusive no nome do sogro, o Conde do MeAL. Não é casual que Carlota alforrie os escravos do Grotão, pois, além de retirar do futuro casamento a sua lógica de negócio - a fazenda destituída de seus "bens" não interessaria à família do noivo -, põe fim à violência reinante. $\mathrm{Na}$ atitude aparentemente monstruosa de Carlota, porque destrutiva, os negros e mulatos têm suas verdadeiras faces restituídas.

32. PENNA. A menina morta, p. 123.

33. PENNA. A menina morta, p. 125.

34. PENNA. A menina morta, p. 381.

35. PENNA. A menina morta, p. 330.

36. PENNA. A menina morta, p. 399. 
Figuras paradoxais, os escravos que trabalham na fazenda, verdadeiras abelhas em colméia, ${ }^{37}$ são os que mais lhe ameaçam a existência, pois são potências destrutivas, presenças a um só tempo necessárias e indesejáveis.

As negras e mulatas não dominam os brancos pelo que revelam, mas principalmente pelo que omitem. A "segunda boca", de Joviana deixa isso evidente: anuncia com sutileza o que não diz. O pouco que se conta - e numa primeira leitura fica-se com a sensação de que quase nada se revela - faz prever o muito que não se conta. Nessa medida, as histórias das mucamas são análogas à do narrador corneliano: todos contam dizendo e não dizendo. Os narradores negaceiam com o leitor, criam uma enorme expectativa de revelações que não se concretizam, prometem o que nunca cumprem. Por isso é preciso aprender a ler o silêncio, perceber o que ele significa ou ao menos o que pode significar. É através de narrativas mal iluminadas, estéreis na aparência, que se vai conhecendo o significado oculto das coisas em Cornélio Penna. O próprio tecido literário toma ares fantasmagóricos: uma imagem com contorno vago e sem conteúdo. É como se as interdições impostas no universo daquilo que é narrado invadissem a narração. E assim como as narradoras daquilo que é narrado transgridem as regras, igualmente o narrador do romance as transgride revelando pouco, deixando para o leitor uma série de lacunas. Aquilo que o narrador omite não precisa necessariamente ser preenchido porque o seu silêncio se apresenta como metáfora do silenciamento ao qual muitos foram obrigados a se sujeitar para sobreviver. Dessa maneira, importa menos saber aonde vai Dona Mariana quando deixa o Grotão, por exemplo, do que saber no que a sua ausência implica. Torna-se irrelevante conhecer a causa da morte da menina: é a sua falta que significa. A memória (re)velada pelas mucamas é fantasmagórica porque é fragmentada, é resíduo disposto conforme as interdições permitem - cabe ao leitor ser cativado ou não por elas.

A narrativa corneliana propõe o não dizer como forma de conhecimento, propõe o espaço "em negro" do mistério como o espaço do saber. A luz, grande metáfora do conhecimento, pode cegar e turvar a apreensão real; algumas coisas só podem ser reveladas no escuro. Quando, no final do romance, Dona Mariana retorna ao Grotão, Carlota já está consciente do espetáculo que havia se desenrolado a sua frente e do qual ela tomara parte como aniquiladora. É

37. PENNA. A menina morta, p. 388.

38. PENNA. A menina morta, p. 342. 
um dia de sol reverberante, tudo está iluminado na fazenda. No entanto, a carruagem que se posta diante da casa-grande é mais um "cofre fechado":

\begin{abstract}
A pesada liteira, como um pequeno mundo de mistério, parara diante do alpendre e ali permaneceu, negra e fechada, sob o esplendor do dia solar. Parecia, cercada pelos liteireiros calados e imóveis, à espera de alguma viajante que deveria surgir do interior da casa para ir se abrigar entre suas cortinas. Mas o incômodo veículo, suspenso em seus varais, trazia em seus flancos o odor das águas vivas e das pedras queimadas de $l u z$, as manchas dos galhos úmidos e pejados de seiva que o tinham fustigado molemente nos longos caminhos percorridos, e os animais a ela atrelados, que deixavam pender as cabeças, o pêlo ainda molhado de suor e coberto de folhas secas, mostravam bem que acabavam de chegar, trazidos por atalhos e desvios apartados. Tinham-se, entretanto, integrado no silêncio enorme do quadrado, apenas interrompido pelos pássaros que passavam e pelo vento morno que agora interrompera o seu fôlego, à espera.

Carlota encostou-se à ombreira do portal e comprimiu o peito onde o coração lhe dava grandes saltos. Houve em seu espírito prodigioso movimento de clareza e descobrimento, capaz de determinar a loucura ou a morte. ${ }^{39}$
\end{abstract}

Mais uma vez Carlota e leitor serão logrados. O narrador parece anunciar uma grande revelação a ser feita a partir do retorno de Dona Mariana, mas ela é pura loucura. Nada dirá, nenhuma palavra será sequer balbuciada, sua boca é "simples e funda sutura". Seus lábios foram como que costurados pela dor e pelo sofrimento. No entanto, como o silêncio significa, sua volta repercute a violência de tudo o que foi e não foi dito anteriormente. A Senhora é o seu resultado, é uma das principais vítimas da sua ação devastadora.

Assim como a linguagem não existe sem o silêncio, tampouco a luz prescinde do escuro. Não se trata de mera oposição, ambos são fundamentais. O escuro vive na penumbra da luz e esta só se faz enquanto tal porque há escuridão. Aos próprios fantasmas, seria impossível existir na escuridão total. É necessário um pouco de iluminação para se poder identificar seus contornos, como é o caso do retrato da menina morta na cena final do romance. Num certo sentido, esse momento se opõe ao do retorno de Dona Mariana, quando é o sol que predomina. A sala

39. PENNA. A menina morta, p. 466. (grifo meu)

40. PENNA. A menina morta, p. 467. 
está escura, Carlota observa o quadro como quem se observa num espelho, tanto que se identifica com a irmã. Um pequeno raio de luz, mais um bruxuleio do que um raio, ilumina fugaz a imagem. A criança, espectro que assombrara o Grotão ao longo da narrativa, absolutamente não existiria se não recebesse alguma iluminação. Tampouco poderia receber luz de forma generosa. É na sombra que se produz o fantasma, entre o conhecer e o não conhecer, nas suas fissuras. Ou entre o ver e o não ver, já que o fantasma não pode ser só claro nem só escuro:

E a luminosidade flutuante em farrapos pela sala, toda se concentrou na figura leve da menina morta que, tendo a cabeça pousada na almofada, parecia sorrir, mas seu sorriso poderia ser apenas o efeito daquela luz pobre, que dentro em pouco deveria cessar de bruxulear, para se apagar para sempre (...).

Vale a pena recordar ainda uma vez a relação entre escravos e barbárie, marcada tanto no discurso do narrador como no de várias personagens. Se o bárbaro é aquele que ao invés de falar de forma inteligivel apenas balbucia, ele é tão fantasma quanto a narrativa que enuncia. Afinal, sua linguagem, código indecifrável - para o mundo supostamente civilizado -, só se faz enquanto experiência malsucedida. O balbucio é o esforço que faz tentando ser o que não é. O bárbaro não é, apenas pretende ser. Porém, retendo a memória da família Albernaz, os negros sujeitam os brancos a uma compreensão do passado diferenciada. Os senhores são colocados num universo labiríntico feito de palavras e de silêncio que lhes é desconhecido, confundindo narrativas enaltecedoras com assustadoras. De repente se percebem perdidos num território aparentemente dominado - o do próprio passado -, já não encontram a saída para as novas histórias que se cruzam com as antigas, negando-as ou reinventando-as. Indecifrável na linguagembalbucio do negro não é o negro: é o branco que se vê naquilo que é narrado e não consegue se reconhecer.

Se o fantasma é projeção da memória, portanto vestígio do passado, a narrativa igualmente o é. As omissões e o silêncio que o narrador (e as narradoras) disseminam funcionam como fantasmas que atormentam o leitor/ouvinte. O romance corneliano se coloca como vestígio de um crime, (re)vela um erro que não se redime, uma culpa que não se expia: a da escravidão.

41. PENNA. A menina morta, p. 471. 
Abstract: In A menina morta by Cornélio Penna, the monstrous is inscribed in the very act of narrating. The novel (the major narrative) comprises a series of minor narratives told by slave women. Both the main narrator and the women narrators reveal while concealing, tell without telling, show while hiding. Each story reveals the monstrosity of the patriarchal and slavocratic system, but never in a straightforward manner. It is left to the reader to decipher the enigmas in order not to be entwined in the endless maze envisaged by the narratives. Keywords: monster, Cornélio Penna, A menina morta.

$$
\text { Referências }
$$

BENJAMIN, Walter. Sobre o conceito da história. In: __. Magia e técnica, arte e política: ensaios sobre literatura e história da cultura. Trad. Sergio Paulo Rouanet. 6. ed. São Paulo: Brasiliense, 1993. p. 222-232. v. 1.

BRANDÃO, Junito de Souza. Mitologia grega. 3. ed. Petrópolis: Vozes, 1987. v. 1.

BRANDÃO, Junito de Souza. Mitologia grega. Petrópolis: Vozes, 1987. v. 3.

CARROLL, Noel. A filosofia do horror ou paradoxos do coração. Trad. Roberto Leal Ferreira. Campinas: Papirus, 1999.

FOUCAULT, Michel. Soberania e disciplina. In: ___. Microfísica do poder. Trad. Roberto Machado. Rio de Janeiro: Graal, 1979. p. 179-191.

LIMA, Luiz Costa. A perversão do trapezista: o romance em Cornélio Penna. Rio de Janeiro: Imago, 1976.

LUDMER, Josefina. O corpo do delito: um manual. Trad. Maria Antonieta Pereira. Belo Horizonte: Ed. UFMG, 2002.

MIRANDA, Wander Melo. Posfácio. In: PENNA, Cornélio. A menina morta. Rio de Janeiro: Artium, 1997. p. 472-482.

NAZARIO, Luiz. Da natureza dos monstros. São Paulo: Arte \& Ciência, 1998.

ORLANDI, Eni. As formas do silêncio: no movimento dos sentidos. 4. ed. Campinas: Ed. Unicamp, 1997.

PENNA, Cornélio. A menina morta. Rio de Janeiro: Artium, 1997.

RICCEUR, Paul. Tempo e narrativa. Trad. Constança Marcondes Cesar. Campinas: Papirus, 1994. v. 1.

RICCEUR, Paul. Tempo e narrativa. Trad. Marina Appenzeller. Campinas: Papirus, 1995. v. 2 .

RICCEUR, Paul. Tempo e narrativa. Trad. Roberto Leal Ferreira. Campinas: Papirus, 1997. v. 3.

SANTOS, Josalba Fabiana dos. Fronteiras da nação em Cornélio Penna. Belo Horizonte, 2004. Tese (Doutorado em Estudos Literários) - Universidade Federal de Minas Gerais.

SANTOS, Josalba Fabiana dos. Monstros e duplos em A menina morta. In: JEHA, Julio (Org.). Monstros e monstruosidades na literatura. Belo Horizonte: Ed. UFMG, 2007. p. $125-145$. 